\title{
OSTEOGENIC DIFFERENTIATION OF BONE MARROW-DERIVED MESENCHYMAL STROMAL CELLS ON BONE-DERIVED SCAFFOLDS: EFFECT OF MICROVIBRATION AND ROLE OF ERK1/2 ACTIVATION
}

\author{
Yi Zhou ${ }^{1,2}$, Xiaoxu Guan ${ }^{1}$, Zhuoli Zhu', Shanshan Gao', Chunxiang Zhang ${ }^{1}$, Chiquan $\mathrm{Li}^{3}$, Kunpeng Zhou ${ }^{4}$, \\ Weiwei Hou ${ }^{1}$ and Haiyang $\mathrm{Yu}^{*, 2}$ \\ ${ }^{1}$ State Key Laboratory of Oral Diseases, Sichuan University, Chengdu, 610041, P.R. China \\ ${ }^{2}$ West China Hospital of Stomatology, Sichuan University, Chengdu, 610041, P.R. China \\ ${ }^{3}$ Beijing Dede Chuangye Technology Company Limited, Beijing, 100085, P.R. China \\ ${ }^{4}$ Simcere Pharmaceutical Group, Nanjing, 210042, P.R. China
}

\begin{abstract}
Although in vivo studies have shown that low-magnitude, high-frequency (LMHF) vibration (LM: < $1 \times$ g; HF: 20$90 \mathrm{~Hz}$ ) exhibits anabolic effects on skeletal homeostasis, the underlying cellular/molecular regulation involved in bone adaptation to LMHF vibration is little known. In this report, we tested the effects of microvibration (magnitude: $0.3 \times \mathrm{g}$, frequency: $40 \mathrm{~Hz}$, amplitude: \pm 50 $\mu \mathrm{m}, 30 \mathrm{~min} / 12 \mathrm{~h}$ ) on proliferation and osteodifferentiation of bone marrow-derived mesenchymal stromal cells (BMSCs) seeded on human bone-derived scaffolds. The scaffolds were prepared by partial demineralisation and deproteinisation. BMSCs were allowed to attach to the scaffolds for 3 days. Morphological study showed that spindle-shaped BMSCs almost completely covered the surface of bone-derived scaffold and these cells expressed higher ALP activity than those cultured on plates. After microvibration treatment, BMSC proliferation was decreased on day 7 and 10; however, numbers of genes and proteins expressed during osteogenesis, including Cbfa1, ALP, collagen I and osteocalcin were greatly increased. ERK $1 / 2$ activation was involved in microvibration-induced BMSC osteogenesis. Taken together, this study suggests that bone-derived scaffolds have good biocompatibility and show osteoinductive properties. By increasing the osteogenic lineage commitment of BMSCs and enhancing osteogenic gene expressions, microvibration promotes BMSC differentiation and increase bone formation of BMSCs seeded on bone-derived scaffolds. Moreover, ERK1/2 pathway plays an important role in microvibrationinduced osteogenesis in BMSC cellular scaffolds.
\end{abstract}

Keywords: Bone-derived scaffold, bone marrow-derived mesenchymal stromal cells, microvibration, osteogenesis, ERK1/2.

*Address for correspondence:

Haiyang $\mathrm{Yu}$

West China Hospital of Stomatology

Sichuan University

Chengdu, 610041, P.R. China

Telephone/FAX Number: 86-028-85502869

E-mail: yhyang6812@scu.edu.cn
Introduction

Current consensus for bone tissue engineering includes three essential elements, i.e., biomaterial scaffold, osteogenic cell lineage and bone inducing factors (e.g., mechanical stimulus, Ashammakhi and Ferretti, 2003; Khan et al., 2005; Mistry and Mikos, 2005). Scaffold materials should provide the support for cell attachment and have osteoinductive property (Langer and Vacanti, 1993; Ashammakhi and Ferretti, 2003). Due to the limited supply and donor-site morbidity of autogenous bone grafts, different physical structures and insufficient osteoinductive ability of synthetic materials (Ashammakhi and Ferretti, 2003; Silber et al., 2003), scaffolds derived from different individuals (allografts) and species (xenografts) provide a promising resource and approach to address the significant drawbacks of existing scaffolds, because these scaffolds have similar structures to autogenous bone (Salkeld et al., 2001; Simion et al., 2004). Additionally, with the proper chemical and physical process on these bone materials, including demineralisation and deproteinisation (Tadjoedin et al., 2003; Xu et al., 2003), we can minimise immune rejection of bone-derived scaffolds (Deijkers et al., 1997; NormanTaylor and Villar, 1997), but preserve their osteoinductive abilities and maintain their physical structures.

However, the simple loading of osteogenic cell sources (e.g., BMSCs) to bone-derived scaffolds has largely been limited by the challenge of lacking stimulus to promote bone formation. Since bone is a dynamic tissue and constantly remoulding to adapt mechanical loading (Burger and Klein-Nulend, 1999; Huiskes et al., 2000; Frost, 2003). Numerous studies have confirmed that a variety of mechanical stimuli, including fluid flow, hydrostatic pressure, mechanical stretching and vibration, influence bone remoulding through the coupling of osteoblastic and osteoclastic activities (Weyts et al., 2002; Huang et al., 2009; Hess et al., 2010; Lau et al., 2010). The vibration with proper combination of frequency and magnitude can induce bone anabolic response (Turner et al., 1995; Rubin et al., 2002; Tanaka et al., 2003; Rubin et al., 2004; Rubin et al., 2007). Low-magnitude (LM: $<1 \times \mathrm{g}, \mathrm{g}=9.81 \mathrm{~m} / \mathrm{s}^{2}$ ), high-frequency (HF: 20-90 $\mathrm{Hz}$ ) vibrations have been demonstrated by studies that such kinds of mechanical stimuli exhibit anabolic roles on bone homeostasis in animals (Rubin et al., 2002; Garman et al., 2007; Rubin et al., 2007), postmenopausal osteoporotic women (Rubin et al., 2004), and children with musculoskeletal diseases such as cerebral palsy 

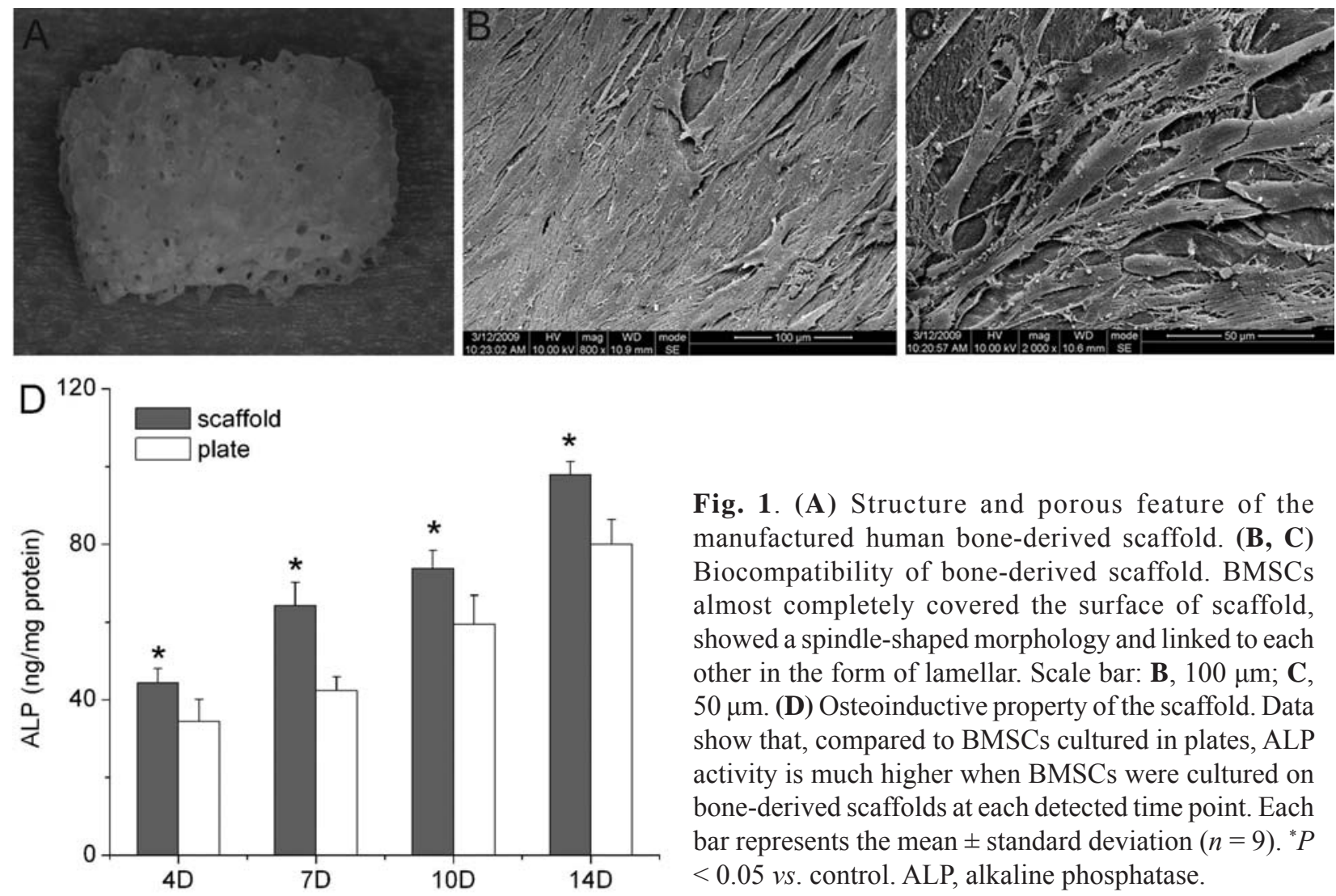

Fig. 1. (A) Structure and porous feature of the manufactured human bone-derived scaffold. (B, C) Biocompatibility of bone-derived scaffold. BMSCs almost completely covered the surface of scaffold, showed a spindle-shaped morphology and linked to each other in the form of lamellar. Scale bar: B, $100 \mu \mathrm{m}$; C, $50 \mu \mathrm{m}$. (D) Osteoinductive property of the scaffold. Data show that, compared to BMSCs cultured in plates, ALP activity is much higher when BMSCs were cultured on bone-derived scaffolds at each detected time point. Each bar represents the mean \pm standard deviation $(n=9) .{ }^{*} P$ $<0.05$ vs. control. ALP, alkaline phosphatase.

(Ward et al., 2004). However, the underlying mechanism of the anabolic and anti-resorptive role of LMHF vibration on bone remains unknown. Lau et al. (2010) recently reported that osteocytes are the sensing cells to LMHF vibration and produce soluble factors that suppress osteoclast formation. Additionally, Patel et al. (2009) observed that LMHF vibration is capable of stimulating osteoblast differentiation. However, whether LMHF vibration exhibits any effect on BMSC differentiation, the progenitors of osteocytes and osteoblasts, is currently unknown. We thus put forward a hypothesis that LMHF vibration may be able to regulate the osteodifferentiation of BMSCs. The postulation is supported by the study of Dumas et al. (2010), which showed the indirect evidence that extracellular matrix produced by osteoblasts under LMHF vibration is favourable to BMSC osteodifferentiation.

The differentiation of BMSCs into osteoblasts is primarily controlled by Cbfa1/Runx2 (Ducy et al., 1997). Cbfa1/Runx2 phosphorylation and activation is mediated by ERK1/2 (Xiao et al., 2000; Xiao et al., 2002). The activation of ERK1/2 has been demonstrated by studies to be involved in BMSC and osteoblast differentiation in response to various mechanical stimuli, including shock wave, hydrostatic pressure, fluid flow and cyclic strain (Wang et al., 2002; Weyts et al., 2002; Simmons et al., 2003; Kim et al., 2007). Moreover, ERK1/2 activation is also associated with collagen synthesis, bone specific protein production and calcium deposition (Lai et al., 2001; Wang et al., 2002; Weyts et al., 2002; Simmons et al., 2003; Kim et al., 2007). This may suggest that ERK $1 / 2$ is an essential pathway in the mechanotransduction process. We therefore hypothesized that ERK1/2 activation may also play an essential role in LMHF vibration mediated-BMSC osteodifferentiation.

Here, it is relevant to note that the in vitro data presented in two studies by Lau et al. (2010) and Patel et al. (2009) to provide an explanation for the anabolic and anti-resorptive role of LMHF vibration observed in vivo, are obtained from bone cells in two dimensional (2D) cultures. However, investigating the role of LMHF vibration on osteogenic cells in $3 \mathrm{D}$ cultures might mimic in vivo conditions. Therefore, we subjected BMSCs seeded on human bone-derived scaffolds (3D) to LMHF vibration at a magnitude of $0.3 \times \mathrm{g}$ and a frequency of $40 \mathrm{~Hz}$. To test our hypotheses, we examined the cell proliferation, osteogenic markers, and whether ERK1/2 activation is involved in osteogenesis process after LMHF vibration treatment. Since the amplitude of this kind of LMHF vibration is \pm $50 \mu \mathrm{m}$, we defined it as microvibration.

\section{Materials and Methods}

\section{Animals}

Sprague-Dawley rats (8-10 weeks) were purchased from the Laboratorial Animal Center, Huaxi Medical Centre, Sichuan University (Chengdu, China) and received care according to the Guide for the Care and Use of Laboratory Animals issued by the US National Institute of Health (NIH Publication NO. 85-23). The experimental procedures on rats were approved by the Care and Use of Experiment Animals Committee of Huaxi Medical Centre, Sichuan University, Chengdu, China. 


\section{Isolation and culture of rat BMSCs}

BMSCs were isolated and cultured as previously described (Zhou et al., 2010). Briefly, rats were anaesthetised with Nembutal (intramuscular: $25 \mathrm{mg} \mathrm{kg}^{-1}$; Sigma-Aldrich, St. Louis, MO, USA) and killed by heart puncture, the tibias and femurs were then dissected. BMSCs were harvested by flushing out the bone marrow with $1 \%$ low glucose Dulbecco's Modified Eagle Medium (L-DMEM; Gibco BRL, Gaithersburg, MD, USA) in a syringe. The cells were resuspended and placed in the culture medium containing $10 \%$ foetal bovine serum (FBS; Gibco BRL), 100 units $\mathrm{mL}^{-1}$ penicillin (Sigma-Aldrich) and $100 \mu \mathrm{g} \mathrm{mL}^{-1}$ streptomycin (Sigma-Aldrich), and grown in a humidified atmosphere of $5 \% \mathrm{CO}_{2}$ at $37{ }^{\circ} \mathrm{C}$. The culture medium was replenished every $2 \mathrm{~d}$ until the cells were $80-90 \%$ confluent; then cells were detached with $0.25 \%$ trypsin (Gibco BRL) and subcultured. The passages 2-3 of BMSCs were used in all experiments.

\section{Preparation of human bone-derived scaffold}

Frozen tibias and femurs of human cadavers were obtained from the Bone Bank, Sichuan Province Tissue Bank, with the approval of the ethics committee, Chengdu, Sichuan, China. The bones were cut into blocks with a size of $18 \times 10 \times 8 \mathrm{~mm}$, which consisted of both cancellous and cortical bone tissue. The blocks were washed with physiological saline, and processed a series of physical and chemical treatments (Tadjoedin et al., 2003; Xu et al., 2003; Mauney et al., 2005), including partial deproteinisation, partial demineralisation and lyophilisation. Briefly, bone blocks were sequentially immersed in $10 \%$ hydrogen peroxide (Sigma-Aldrich) for $1 \mathrm{~d}$ at $38{ }^{\circ} \mathrm{C}$, $0.6 \mathrm{~N}$ hydrochloric acid (Sigma-Aldrich) for $4 \mathrm{~h}$ at room temperature, chloroform/methanol (1:1; Sigma-Aldrich) for $1 \mathrm{~h}$ at room temperature, $0.25 \%$ trypsin for $12 \mathrm{~h}$ at 4 ${ }^{\circ} \mathrm{C}$ and finally $0.5 \%$ SDS (Sigma-Aldrich) for $6 \mathrm{~h}$ at room temperature, followed by lyophilisation and sterilisation using ${ }^{60} \mathrm{Co} \gamma$-ray irradiation $\left(20-25 \times 10^{3} \mathrm{~Gy}\right.$; Beijing Dede Chuangye Technology Company Limited, Beijing, China). The processed scaffolds were then trimmed to a size of $13.4 \times 8 \times 5 \mathrm{~mm}$, without cortical structures (Fig. $1 \mathrm{~A})$ and tightly placed in 24 -well plates. The pore size of the processed scaffolds is $90-700 \mu \mathrm{m}$ and the interval porosity is $88 \%$.

\section{Culture of BMSCs on bone-derived scaffold}

The bone-derived scaffolds were soaked in DMEM for $1 \mathrm{~d}$ prior to cell seeding. The excessive volume of medium in the scaffolds was removed using sterile cotton balls and $100 \mu \mathrm{L}$ BMSCs suspension $\left(1 \times 10^{7}\right.$ cells $\left.\mathrm{mL}^{-1}\right)$ was slowly dripped onto scaffolds to avoid overflow. These scaffolds seeded with BMSCs were incubated in a humidified atmosphere of $5 \% \mathrm{CO}_{2}$ at $37{ }^{\circ} \mathrm{C}$ for $3 \mathrm{~h}$, after which the additional culture medium was added to fully cover the scaffolds. To make sure cells can attach to scaffolds, the composites needed to be further incubated in the humidified atmosphere of $5 \% \mathrm{CO}_{2}$ at $37^{\circ} \mathrm{C}$ for $3 \mathrm{~d}$. BMSC cellular scaffolds were then prepared for scanning electron microscopy (SEM) or microvibration experiments.

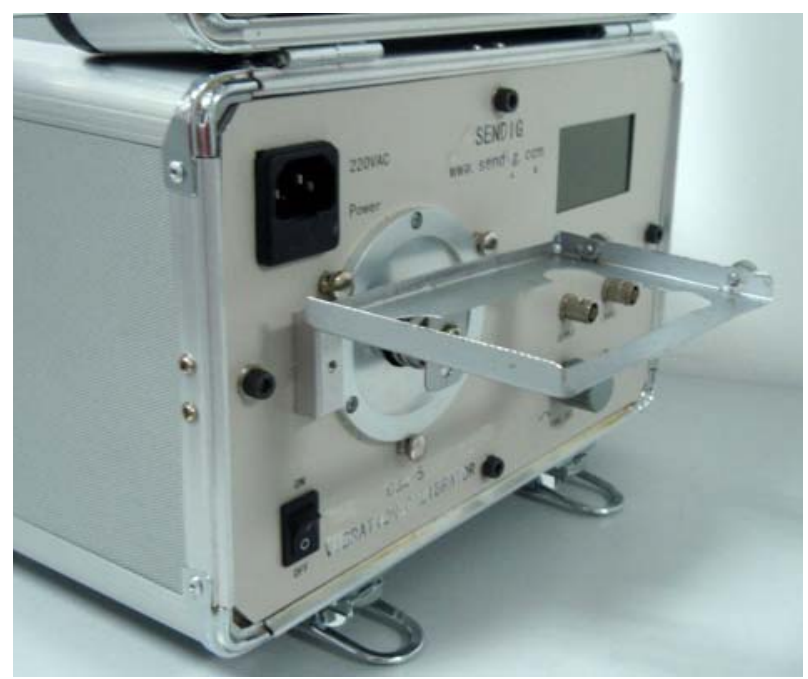

Fig. 2. View of GJX-5 vibration sensor and fixture.

\section{GJX-5 vibration sensor}

The panel of GJX-5 vibration sensor (Beijing Sending Technology, Beijing, China; Fig. 2) has a platform for the fixture to be mounted on (Fig. 2). The 24-well plates cultured with BMSCs cellular scaffolds can be placed tightly in the fixture. Once the fixture was in parallel with the ground, BMSC cultures received mechanical stimuli (magnitude: $0.3 \times \mathrm{g}$, frequency: $40 \mathrm{~Hz}$, amplitude: $\pm 50 \mu \mathrm{m}$ ) for $30 \mathrm{~min}$ every $12 \mathrm{~h}$ for various time periods as indicated in each experiment.

\section{Microvibration culture $v s$. static culture $v s$. plastic culture}

Cells seeded on scaffolds or in plastic plates $\left(2 \times 10^{4}\right.$ cells/ well) were then randomly divided into microvibration culture and static culture groups, both of which were cultured in a humidified atmosphere of $5 \% \mathrm{CO}_{2}$ at $37^{\circ} \mathrm{C}$ with a change of osteogenic medium (90\% DMEM, $10 \%$ FBS, $10^{-6} \mathrm{M}$ dexamethasone, $10^{-2} \mathrm{M} \beta$-glycerol phosphate and $50 \mu \mathrm{g} / \mathrm{mL}$ ascorbic acid; Sigma) prior to application of mechanical stimulus. After microvibration treatment, all experiments, mRNA and protein collection were performed immediately.

\section{DNA content assay}

The total DNA content in BMSC cellular scaffolds cultured in different environments was assayed by using a Picogreen DNA Quantification kit on day 0, 1, 3, 7, 10 (Molecular Probes, Eugene, OR, USA). DNA was extracted from each scaffold in aliquots of enzymatic cocktail containing $0.1 \%$ collagenase A (Roche, Penzberg, Germany) and 0.1 trypsin at $37^{\circ} \mathrm{C}$ for $2 \mathrm{~h}$, with vortex every $30 \mathrm{~min}$ and followed by three cycles of freeze and thaw. The measurement was conducted following the manufacturer's instructions.

\section{Thymidine incorporation assay}

The proliferation of BMSCs in the scaffolds under different culture conditions were examined on day $0,1,3,7$, and 10. BMSC cellular scaffolds were incubated at $37^{\circ} \mathrm{C}$ for 
$5 \mathrm{~h}$ with addition of $1 \mu \mathrm{Ci}$ of $\left[{ }^{3} \mathrm{H}\right]$-thymidine (Shanghai Institute of Nuclear Research, Shanghai, China). After washing with PBS three times, aliquots of lysis buffer (10 mM Tris-HCl, $1 \mathrm{mM}$ EDTA, $1 \mathrm{mM}$ PMSF, $1 \%$ Triton X-100 and 0.1 \% SDS; Sigma-Aldrich) were used to dissolve cells in the scaffolds. The lysate solutions were added onto glass-fibre filter paper and dried at 37 ${ }^{\circ} \mathrm{C}$. The paper was then immersed in $5 \mathrm{~mL}$ scintillation solution $\left(5 \mathrm{mg} \mathrm{mL}^{-1} 2\right.$, 5-diphenyl oxazole and $0.3 \mathrm{~g}$ $\mathrm{mL}^{-1}$ 1, 4-bis (5-phenyl-2-oxazolyl) benzene dissolved in dimethyl benzene; Sigma-Aldrich) at dark room for 2 h. $\left[{ }^{3} \mathrm{H}\right]$-thymidine incorporation was analysed by using a liquid scintillation analyser (Beckman Coulter, Brea, CA, USA). The results are shown as count per minute (CPM; Zhou et al., 2010).

\section{Quantitative real-time RT-PCR}

Total mRNA was extracted from BMSC cellular scaffolds by adding $1 \mathrm{~mL}$ of RNAiso plus (TAKARA, Dalian, China) on day $1,4,7,10,14,18,22$, and $26.1 \mu \mathrm{g}$ mRNA was then subjected to cDNA synthesis in a $20 \mu \mathrm{L}$ reaction volume containing $0.5 \mu \mathrm{L}$ PrimeScript ${ }^{\mathrm{TM}}$ RT Enzyme Mix I, 0.5 $\mu \mathrm{L}$ oligo dT Primer, 2.0 $\mu \mathrm{L}$ PrimeScript ${ }^{\mathrm{TM}}$ Buffer and 0.5 $\mu \mathrm{L}$ Random 6 mers. The procedures of SYBY Green PCR assay on cDNA samples using $\mathrm{iCycler}_{\mathrm{iQ}} \mathrm{Q}^{\mathrm{TM}}$ Multicolor real-time PCR Detection System (Bio-Rad, Hercules, CA, USA) included initial denaturation at $95^{\circ} \mathrm{C}$ for $10 \mathrm{~s}$, 40 cycles of denaturation at $95^{\circ} \mathrm{C}$ for $5 \mathrm{~s}$, annealing and extension at $60{ }^{\circ} \mathrm{C}$ for $45 \mathrm{~s}$, in a $25 \mu \mathrm{L}$ reaction volume containing $2 \mu \mathrm{L}$ cDNA, $1 \mu \mathrm{L}$ forward primer, $1 \mu \mathrm{L}$ reverse primer, $12.5 \mu \mathrm{L} \mathrm{SYBR}{ }^{\circledR}$ Premix Ex Taq ${ }^{\mathrm{TM}}$, and $8.5 \mu \mathrm{L}$ sterile water. Fluorescence data was analysed by using Optical system software version 3.1 (Bio-Rad) to get CT values. The CT values were calculated in relation to GAPDH CT values by the $2^{-\Delta \Delta \mathrm{CT}}$ method (Zhou et al., 2010).

\section{Western blots}

The Cbfa1/Runx 2 contents in BMSCs cellular scaffolds under different culture conditions were measured on day 4, ERK1/2, phospho-ERK1/2 and tubulin on $30 \mathrm{~min}$, day $1,3,7$. Scaffolds were ground into small pieces with mortar and pestle, and proteins were harvested with lysis solution $(50 \mathrm{mM}$ Tris- $\mathrm{HCl}, 150 \mathrm{mM} \mathrm{NaCl}, 1 \%$ Triton X-100, $0.25 \%$ Na-deoxycholate, $1 \mathrm{mM}$ activated $\mathrm{Na}_{3} \mathrm{VO}_{4}, 1 \mathrm{mM}$ EDTA, $1 \mathrm{mM} \mathrm{NaF}, 1 \mathrm{mM}$ DTT, $1 \mathrm{mM}$ phenylmethylsulphonylfluoride, $1 \mu \mathrm{g} / \mathrm{mL}$ aprotinin, $1 \mu \mathrm{g} /$ $\mathrm{mL}$ leupeptin, and $1 \mu \mathrm{g} / \mathrm{mL}$ pepstatin, $\mathrm{pH}$ 7.4; SigmaAldrich). After centrifugation of cell lysates at $14,000 \mathrm{~g}$ for 15 min at $4{ }^{\circ} \mathrm{C}$, supernatant protein samples were harvested and total protein concentration was determined using BCA protein assay (Pierce, Rockford, IL, USA). The samples were separated on $10 \%$ SDS-PAGE gels and transferred to polyvinylidene difluoride membranes (Roche Diagnostics). These membranes were then immunoblotted with primary antibody at $4{ }^{\circ} \mathrm{C}$ for $12 \mathrm{~h}$. After incubation with horseradish peroxidase-conjugated secondary antibody (Santa Cruz, Santa Cruz, CA, USA) at room temperature for $1 \mathrm{~h}, \mathrm{Cbfa} 1 /$ Runx2, tubulin, ERK1/2 and phospho-ERK1/2 (Santa Cruz; Neven et al., 2010; Li et al., 2010) were visualised using enhanced chemiluminescence reagents (Pierce).
The immunoblots were quantified with Scion Image Beta 4.0.2 software (Scion Corporation, Frederick, MD, USA).

\section{Alkaline phosphatase (ALP) activity assessed by spectrophotometry}

The intracellular ALP activities under different culture conditions were compared on days 4, 7, 10, 14. Cell lysates were obtained as described above. Alkaline phosphatase (ALP) activity was analysed by adding aliquots of lysate solution in a $100 \mu \mathrm{L}$ reaction volume containing 50 $\mathrm{mM}$ p-nitrophenylphosphate (Sigma-Aldrich), $1 \mathrm{mM}$ $\mathrm{MgCl}_{2}$ (Sigma-Aldrich), and $50 \mathrm{mM}$ glycine (SigmaAldrich), at $37{ }^{\circ} \mathrm{C}$ for $30 \mathrm{~min}$. The optical density of catalysate was detected at $405 \mathrm{~nm}$ using SpectraMax 190 spectrophotometer (Molecular Devices, Sunnyvale, CA, USA; Zhou et al., 2010).

\section{Quantitation of osteocalcin (OC) by ${ }^{125} \mathrm{I}$ radioimmunoassay}

After being cultured in two different conditions for 4, 7, 10 and $14 \mathrm{~d}$, the OC content in BMSC cellular scaffolds were assayed as previously described (Gundberg et al., 1998). Briefly, the assay is based on the competition of radioactively labelled OC (Beijing Puer Weiye Biotechnology Company, Beijing, China) and an identical non labelled OC for binding to a specific antibody. In the reaction system, the amount of labelled OC bound to the antibody is conversely proportional to the amount of unlabelled OC. The assays consisted of a known concentration of standard OC or unknown concentrations of OC samples, $2 \times 10^{4} \mathrm{CPM}$ of ${ }^{125} \mathrm{I} \mathrm{OC}$ and $100 \mu \mathrm{L}$ antiserum in assay buffer, according to the manufacturer's instructions. The reaction systems were then incubated at $25^{\circ} \mathrm{C}$ for $20 \mathrm{~h}$ with constant shaking before further detection.

\section{ERK1/2 inhibition study}

To assess the effects of ERK $1 / 2$ inhibition on BMSC osteogenesis, $10 \mu \mathrm{M}$ U0126 (Promega, Madison, WI, USA), an inhibitor of phospho-ERK1/2 (Goueli et al., 1999; Simmons et al., 2003; Kim et al., 2007), was added to the serum-free cell culture media with the purpose of reducing basal ERK1/2 activity $1 \mathrm{~h}$ prior to application of microvibration. BMSC cellular scaffolds were then placed into osteogenic media with or without U0126 and exposed to microvibration for $14 \mathrm{~d}$. The inhibitor was dissolved in dimethylsulphoxide (DMSO; Sigma-Aldrich). The untreated cells were pre-incubated with same amount of $0.04 \%$ DMSO alone. ALP was harvested on day 14 and assayed as described above.

\section{Statistical analysis}

The data were presented as mean \pm standard deviation and statistically analysed using paired Student's $t$-test with SPSS soft ware, version 17.0 (SPSS Inc., Chicago, IL, USA). Statistically significant values were defined as $P<$ 0.05 . Thymidine incorporation assay, DNA content assay, quantitative real-time PCR, Western blot and ERK1/2 inhibition study were repeated from three independent experiments. All other assays were carried out in triplicate with three independent experiments. 


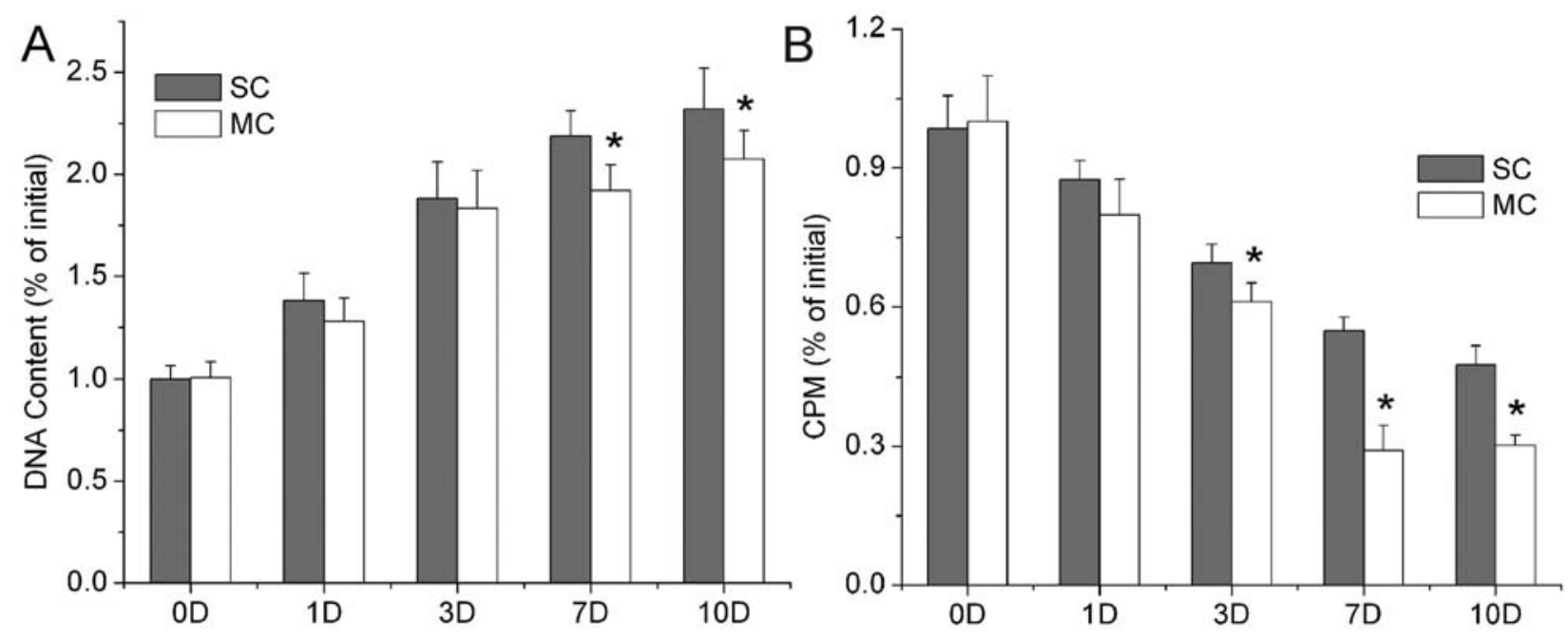

Fig. 3. Effect of microvibration on BMSC proliferation. (A) DNA content: DNA contents in both groups were increased progressively. However, with microvibration treatment, it is lower on day 7 and 10. (B) Thymidine incorporation: BMSC's ability to incorporate thymidine was decreased as culture progress. The inhibitory effect of microvibration on cell's ability to incorporate thymidine was observed on day 3, 7 and 10. Bars represent the mean \pm standard deviation $(n=3) ; * P<0.05$. CPM, count per minute. SC, static culture. MC, microvibration culture.
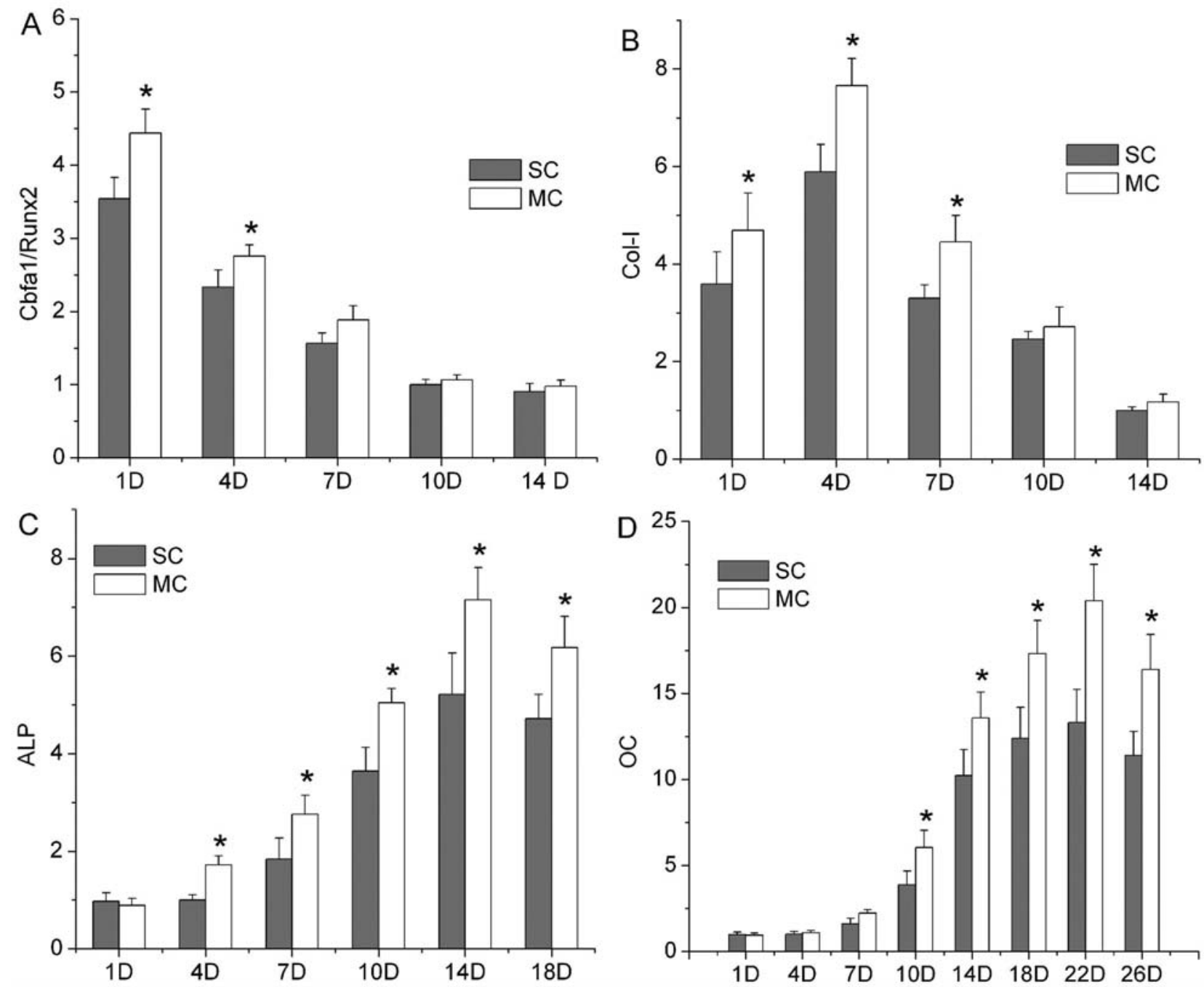

Fig. 4. Effect of microvibration on osteogenic gene expressions in BMSC cellular scaffolds. Cbfa1/Runx2, Col-I, ALP and OC mRNA expressions were assayed on day 1, 4, 7, 10, 14, 18, 22 and 26. Data show that microvibration greatly upregulated these mRNA levels at different stages of osteogenesis. Each bar represents the mean \pm standard deviation $(n=3) ;{ }^{*} P<0.05$. SC, static culture. MC, microvibration culture. Col-I, collagen I. ALP, alkaline phosphatase. OC, osteocalcin. 
A
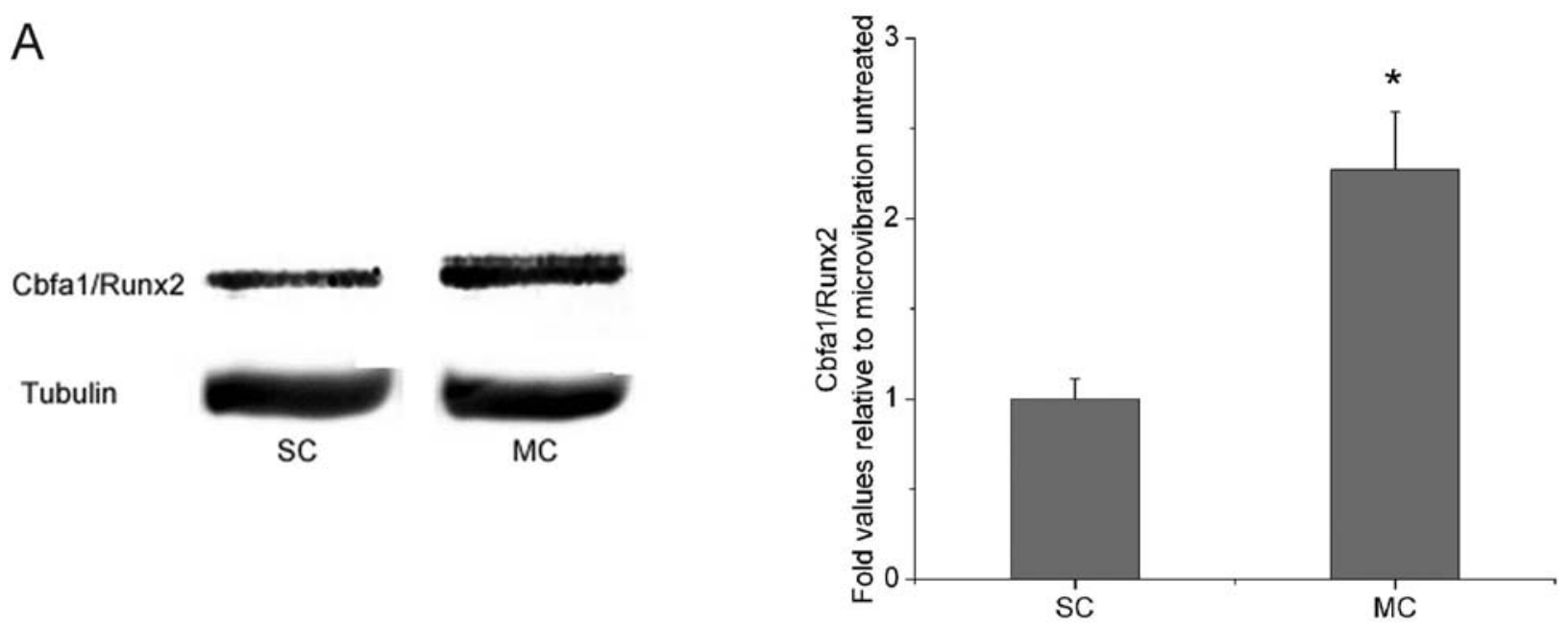

B

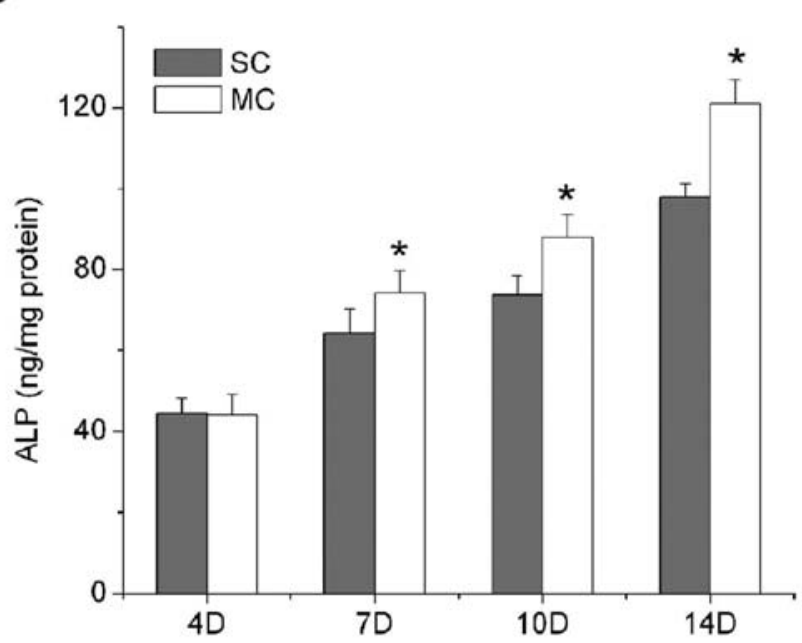

C

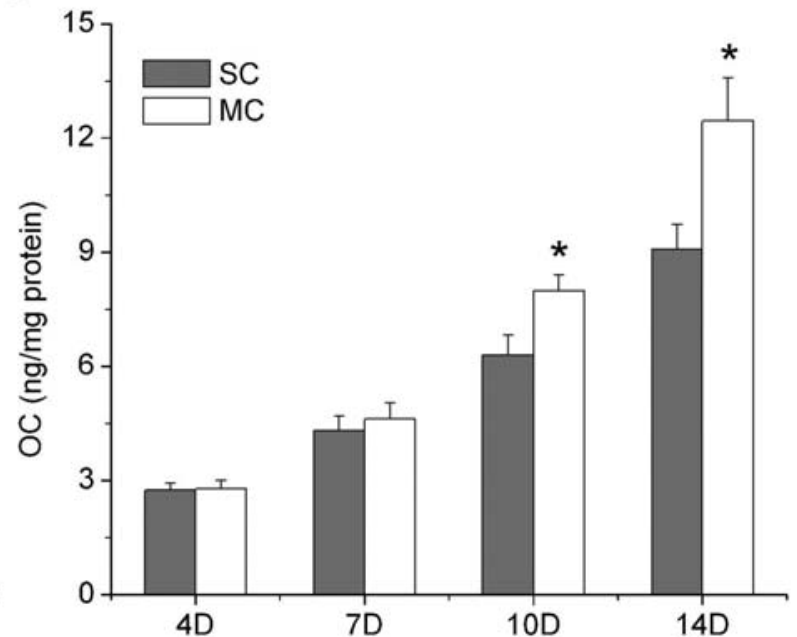

Fig. 5. Effect of microvibration on bone specific proteins. (A) Microvibration significantly increased Cbfa1/Runx2 expression on day 4. Each bar represents the mean \pm standard deviation $(n=3) ;{ }^{*} P<0.05$. (B) ALP activity was upregulated under microvibration culture on day 7, 10 and 14. Each bar represents the mean \pm standard deviation $(n=9) ;{ }^{*} P<0.05$. (C) OC level was enhanced by microvibration on day 10 and 14 . Each bar represents the mean \pm standard deviation $(n=9) ;{ }^{*} P<0.05$. SC, static culture. MC, microvibration culture. ALP, alkaline phosphatase. OC, osteocalcin.

\section{Results}

\section{Biocompatibility and osteoinductive property of bone-derived scaffold}

As observed under SEM, BMSCs almost completely covered the surface of human bone-derived scaffold and showed a spindle-shaped morphology. These cells linked to each other and presented in the form of lamellae (Fig. 1B, C). The observation suggested that bone-derived scaffolds could provide support for BMSCs to attach, implying that scaffolds had good biocompatibility property. To further determine whether the processed scaffolds promoted osteogenesis, BMSCs were cultured in osteogenic medium and ALP activity was assayed on day 4, 7, 10 and 14. In comparison to BMSCs cultured in plates, ALP activity was significantly increased in BMSC cellular scaffolds, suggesting that scaffolds produced as described above had osteoinductive properties (Fig. 1D; $P<0.05$ ).

\section{Decrease in BMSC proliferation in bone-derived scaffolds by microvibration}

The impact of microvibration on BMSC proliferation was assayed by DNA content in each scaffold. As shown in Fig. 3A, total DNA contents in both groups were gradually increased and appeared to reach the maximal levels around day 7. However, the DNA content in microvibration-treated group was lower on day 7 and 10, when compared to control group $(P<0.05)$. To further confirm that microvibration had adverse effect on BMSC proliferation, the ability of BMSCs to incorporate thymidine was estimated on day $0,1,3,7$ and 10. As shown in Fig. 3B, the thymidine incorporations in both groups were gradually decreased in a time-dependent manner. However, the ability for cells to incorporate thymidine in microvibration-treated group was significantly inhibited on day 3, 7 and 10, compared to the control group $(P<0.05)$. 


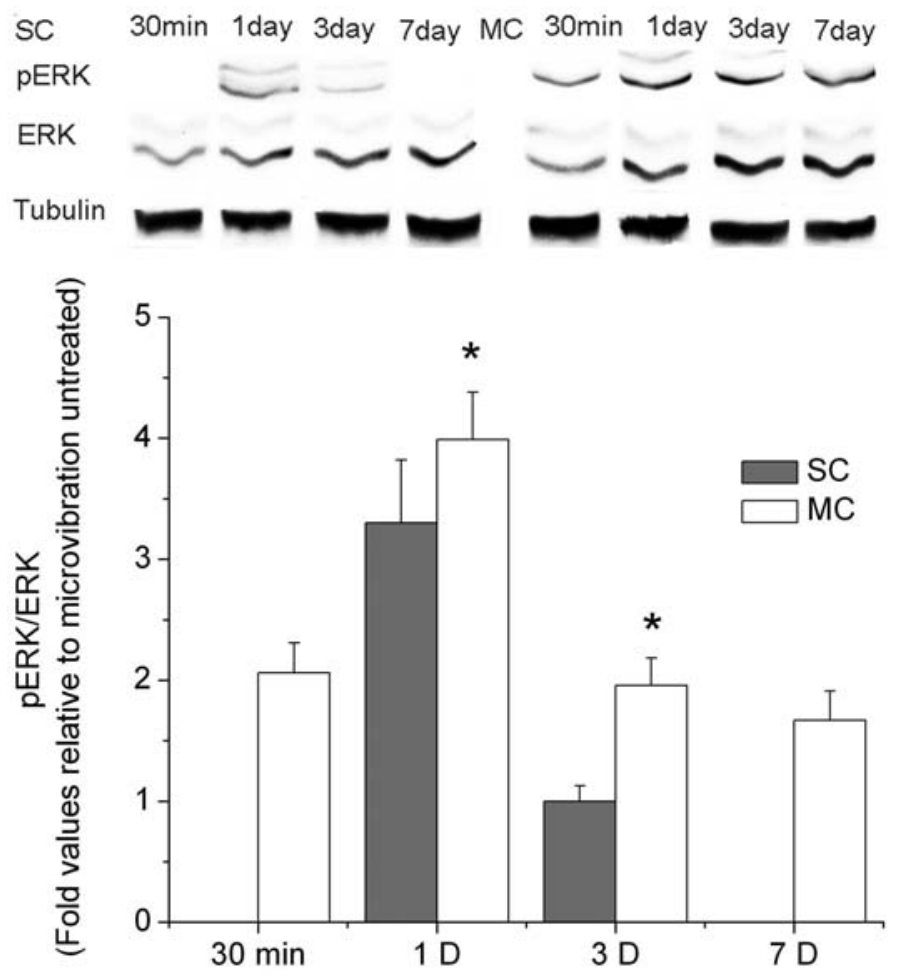

Fig. 6. pERK1/2 was upregulated and sustained over time in the presence of microvibration. Data show that microvibration induced ERK1/2 activation at $30 \mathrm{~min}$ and the phosphorylation of ERK1/2 was sustained more time when compared to microvibration-untreated group. Bars represent the mean \pm standard deviation $(n=3) ; * P<0.05$. SC, static culture. MC, microvibration culture.

\section{Changes in mRNA expression of BMSCs in bone- derived scaffolds by microvibration}

To investigate whether microvibration affected BMSC osteogenic differentiation, genes associated with osteogenesis, including Cbfa1/Runx2, collagen I (Col-I), ALP and OC, were measured by real-time RT-PCR on day 1, 4, 7, 10, 14, 18, 22 and 26. Microvibration-stimulated Cbfa1/Runx2 mRNA expression was apparent on the 1st day (Fig. 4A; $P<0.05$ ). Although the expression of Cbfa1/ Runx2 showed no obvious difference on day 7, 10 or 14 (Fig. 4A; $P>0.05$ ), the elevated level of Cbfa1/Runx2 mRNA lasted for 3 days (Fig. 4A; $P<0.05$ ). Similarly, with microvibration treatment, the mRNA expression of Col-I showed a marked accumulation on day 1, 4 and 7 (Fig. 4B; $P<0.05$ ); ALP mRNA expression was also significantly increased after microvibration exposure for 4, 7, 10 and $14 \mathrm{~d}$ (Fig. 4C; $P<0.05$ ). The exposure of BMSC cellular scaffolds to microvibration induced an increase of OC mRNA expression on day 10, 14, 18, 22 and 26 (Fig. 4D; $P<0.05$ ), although no visible difference of OC mRNA expression was observed on day 1,4 or 7 (Fig. 4D; $P>0.05$ ).

\section{Increased expression of bone specific proteins in BMSC cellular scaffolds by microvibration}

The favourable effects of microvibration on osteogenesis were further testified by the increased expressions of bone specific proteins. As shown in Fig. 5A, western blot revealed that $\mathrm{Cbfa} 1 / \mathrm{Runx} 2$ was greatly enhanced under microvibration culture $(P<0.05)$. Moreover,

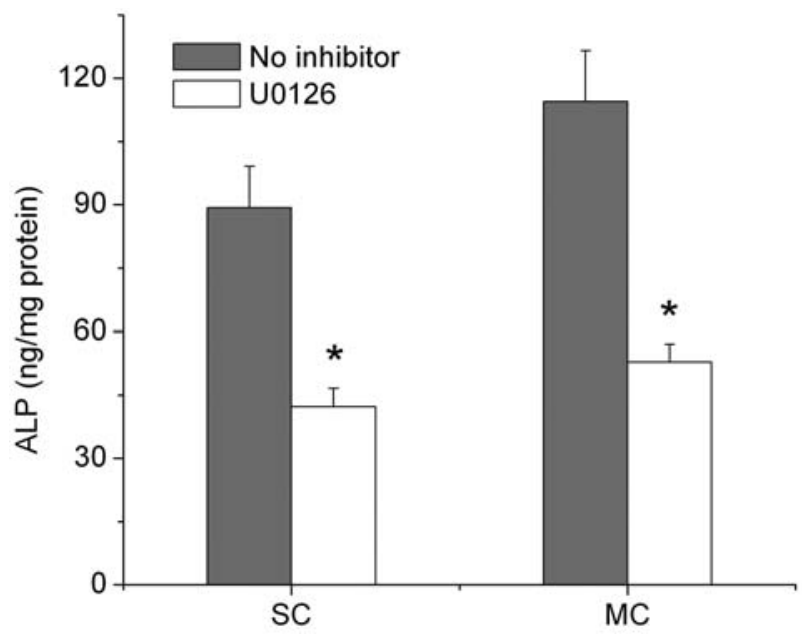

Fig. 7. ERK1/2 pathway was involved both in scaffoldand microvibration-stimulated osteogenesis. Data show that ALP activity was significantly inhibited when BMSCs were treated with U0126 inhibitor regardless of microvibration treatment. Bars represent the mean \pm standard deviation $(n=3) ; * P<0.05$. SC, static culture. $\mathrm{MC}$, microvibration culture. ALP, alkaline phosphatase.

microvibration also resulted in an increase of ALP activity with a time course similar to that observed in ALP mRNA expression from day 1 to day 14 (Fig. 5B; $P<0.05$ ). The pattern of OC protein up-regulation also paralleled that of an increase in OC mRNA expression from day 1 to day 14 (Fig. 5C; $P<0.05$ ). 


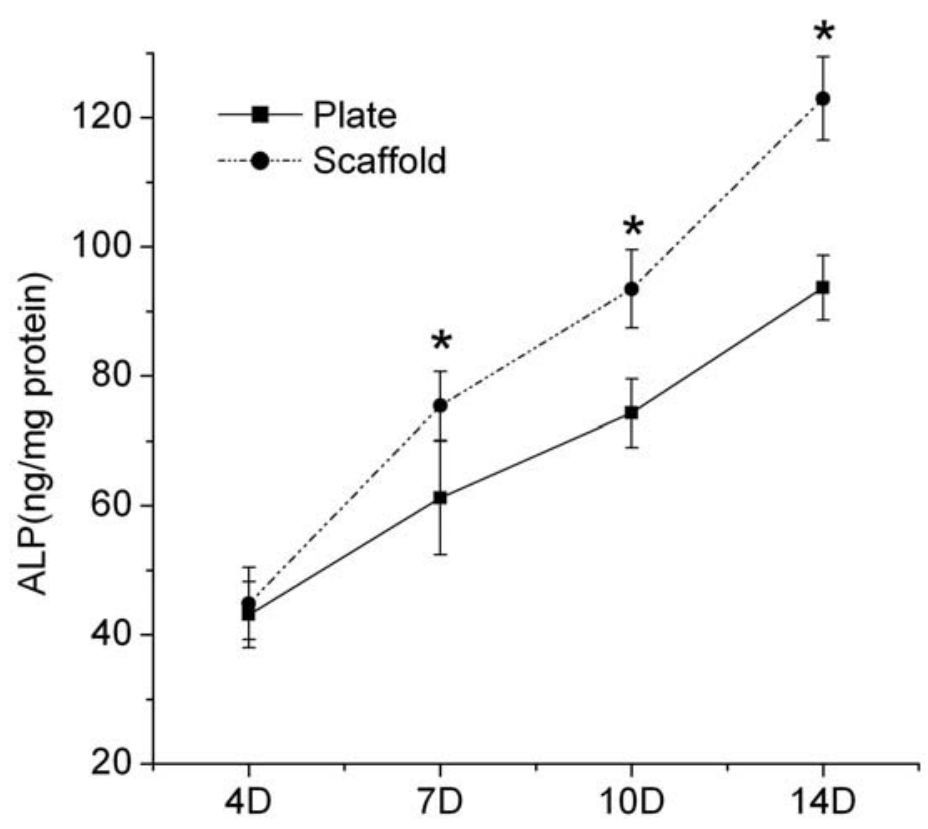

Fig. 8. ALP activity was increased when the cells were cultured in $3 \mathrm{D}$. The data show that, compared to BMSCs cultured in plates with microvibration treatment, the ALP activity is much higher when BMSCs were seeded on bonederived scaffolds and simultaneously treated with microvibration. Bars represent the mean \pm standard deviation $(n=$ 9); ${ }^{*} P<0.05$. ALP, alkaline phosphatase.

\section{Involvement of ERK1/2 activation in microvibration- increased osteogenesis}

Since many studies have demonstrated that mechanical stimuli-induced ERK1/2 activation is involved in various osteogenic responses (Lai et al., 2001; Ziros et al., 2002), western blot analysis was performed to determine whether ERK1/2 pathway was responsible for the increased osteogenesis stimulated by microvibration. As shown in Fig. 6, microvibration stimulus induced the phosphorylation of ERK $1 / 2$ at $30 \mathrm{~min}$, but no phosphorylated ERK1/2 was detected in the static culture. The activation of ERK1/2 was increased or sustained over time in the presence of microvibration $(P<0.05)$, although ERK1/2 phosphorylation was observed in static culture on day 1 and 3. To further confirm the involvement of ERK1/2 in the microvibration-induced osteogenesis, $10 \mu \mathrm{M} \mathrm{U} 0126$, an inhibitor of phospho-ERK1/2, was added to BMSC cellular scaffolds and ALP activity was measured on day 14. As shown in Fig. 7, ALP activity was significantly inhibited in the treated groups $(P<0.05)$, implying that ERK1/2 pathway plays an important role both in scaffoldand microvibration-induced osteogenesis.

\section{Discussion}

In this work, we examined the potential cellular and molecular regulation by which microvibration induced BMSC osteodifferentiation in 3D culturing environment. We have demonstrated that BMSCs seeded on modified bone-derived scaffolds responded to microvibration at both transcript and protein levels during osteogenesis, and EKR1/2 activation was responsible for the microvibrationinduced osteogenesis.
Recently, the most commonly employed approaches used for manufacturing allograft bones included demineralisation and deproteinisation (Tadjoedin et al., 2003; Xu et al., 2003; Mauney et al., 2005). Studies have demonstrated that properly controlling the balance of demineralisation and deproteinisation can preserve or improve the osteoinductive properties of bone scaffolds (Ashammakhi and Ferretti, 2003; Mistry and Mikos, 2005). The reason for these optimised scaffolds may be that the process can expose both soluble and insoluble osteogenic factors from the calcified matrix, including bone morphogenetic proteins and other non-collagenous proteins (Rosenthal et al., 1999; Colnot et al., 2005). To obtain partially or fully demineralised scaffolds, cancellous bone needs to be immersed in hydrochloric acid for 15 min and $12 \mathrm{~h}$, respectively (Mauney et al., 2005). The partially demineralised bone-derived scaffold processed in our study is obtained by hydrochloric acid treatment for $4 \mathrm{~h}$. Therefore, the osteogenic factors may be exposed more within the partially demineralised scaffolds even after partial deproteinisation and thus mainly contribute to the osteoinductive property. This property was demonstrated by ALP activity, which is much higher in BMSC cellular scaffolds compared to those cultured in plastic plates. In addition, the porous structures in scaffolds can easily support the localization, adhesion and growth of xenogenic cells (rat BMSCs), implying that the produced scaffolds show good biocompatibility.

Microvibration caused a reduction of BMSC proliferation in our study. Oh et al. (2010) also demonstrated that vibration was capable of inhibiting 3T3-L1 cell proliferation after exposure to vibration for 2 or $3 \mathrm{~d}$. However, Patel et al. (2009) found no effect of LMHF vibration on $2 \mathrm{~T} 3$ cell proliferation. The inconsistency for 
the effects of LMHF vibration on cell proliferation may be due to different cell types, culturing conditions and vibration protocols. Interestingly, BMSC proliferation in our study was gradually decreased and seemed to cease on day 7 , regardless of microvibration treatment. Since the concomitant increase in cell differentiation is generally accompanied by a parallel reduction in cell growth (Franceschi, 1999), the arrest of cell growth indicates the stimulation of BMSC osteogenic differentiation in both two groups (see below).

The osteogenic differentiation of the cells is usually divided into three discrete stages: commitment to osteogenic lineage, matrix synthesis, and matrix mineralisation (Beck, 2003). Cbfa1/Runx 2 is an essential transcriptional activator for osteogenic lineage commitment (Ducy et al., 1997). It has been demonstrated that Cbfa1/Runx2 knockout could result in the impairment of bone formation (Komori et al., 1997). The enhancement of Cbfa1/Runx2 expression induced by microvibration (frequency: $40 \mathrm{~Hz}$ ) on day 1 and 4 suggests that microvibration can affect osteogenesis at early stage by increasing the commitment of BMSCs to osteogenic lineage. On the other hand, Oh et al. (2010) reported that vibration at $20 \mathrm{~Hz}$ and $30 \mathrm{~Hz}$ enhances cell commitment to adipogenic lineage as demonstrated by increased adipogenic markers, but vibration at 40 $\mathrm{Hz}$ is unable to induce cell adipogenic differentiation. Taken together, these data may imply the existence of a frequency-dependent effect of vibration on determining the cell commitment to different lineages. The hypothesis is further supported by in vivo LMHF vibration reports, where vibration at $90 \mathrm{~Hz}$ is more anabolic than vibration at $45 \mathrm{~Hz}$ in ovariectomised rats (Judex et al., 2007). Moreover, in contrast to the role of low frequency $(20-30 \mathrm{~Hz})$ vibration in inducing cell adipogenic differentiation (Oh et al., 2010), vibration at high frequency $(90 \mathrm{~Hz})$ in in vivo animal studies favours cell osteogenic differentiation but inhibits adipogenic differentiation (Rubin et al., 2007; Luu et al., 2009). Since the concomitant increase in cell differentiation is generally accompanied by a parallel reduction in cell proliferation (Franceschi, 1999), the increased commitment of BMSCs to osteogenic lineage in microvibration culture, as demonstrated by increased Cbfa1/Runx2 expression, can partially explain the inhibitory effect of microvibration on BMSC proliferation (Franceschi, 1999). The increased matrix synthesis and maturation by microvibration was shown by elevated expressions of the middle (Col-I, ALP) and late (OC) markers, as well as their proteins.

The osteogenic cells usually follow similar paths to differentiation and exhibit a similar pattern and time frame of gene expression. Cbfa1/Runx2 is usually highly expressed at early stage (commitment to osteogenic lineage), Col-I and ALP at the middle stage (matrix synthesis) and OC at the late stage (matrix mineralisation) during osteogenesis (Franceschi, 1999; Beck, 2003). Based on the results of PCR analysis, the peak levels of Cbfa1/ Runx2 expression in BMSCs without microvibration exposure is observed at day 1 , Col-I at day 4 , ALP at day 14 , and $\mathrm{OC}$ at day 22. The gene expression presented in BMSC cellular scaffolds under static culture exhibits the pattern similar to the one occurring in osteogenic differentiation (Franceschi, 1999), implying that scaffold is favourable to osteogenic differentiation and further confirming the osteoinductive property of scaffold. Interestingly, microvibration can enhance the peak levels of these genes and intensify the pattern occurred in osteogenic differentiation. The observation could thus prove that microvibration is beneficial for osteogenesis.

$3 \mathrm{D}$ culture has been demonstrated to promote cell osteogenic differentiation and mineralisation (Kinoshita et al., 1999; Rattner et al., 2000). To test the advantage of $3 \mathrm{D}$ culture on osteogenic differentiation in response to LMHF vibration, ALP activity was measured on day 14. As shown in Fig. 8, compared to BMSCs cultured in plates under microvibration, ALP activity is elevated when BMSCs were cultured on bone-derived scaffolds and simultaneously treated with microvibration.

In response to mechanical stimuli, ERK1/2 activation has been demonstrated in many studies to play an essential role in cell osteogenic differentiation (Wang et al., 2002; Weyts et al., 2002; Simmons et al., 2003; Kim et al., 2007). Since microvibration is capable of increasing Cbfa1/Runx 2 expression, of which the phosphorylation and activation is regulated by ERK1/2 (Xiao et al., 2000; Xiao et al., 2002), we postulated that ERK1/2 activation may be also involved in microvibration-mediated BMSC osteodifferentiation. The novel finding that microvibration-induced BMSC osteodifferentiation on bone-derived scaffolds is via ERK1/2 signalling further confirmed the essential role of ERK1/2 pathway in cell osteogenic differentiation during the mechanotransduction process. In our study, blockade of ERK1/2 phosphorylation with U0126 downregulated ALP activity in BMSC cellular scaffolds without microvibration exposure, implying that ERK1/2 pathway also plays a role in the scaffold osteoinductive property. The hypothesis is supported by previous studies that the increased osteogenic differentiation by cell-matrix interactions also involves ERK1/2 activation (Xiao et al., 2000; Xiao et al., 2002). Taken together, these data indicates that ERK1/2 pathway may be not only an essential signal for mechanical stimuli, but also a common mediator for non-mechanical signal.

Osteoblasts and adipocytes are two major lineages differentiating from MSCs and the relationship is reciprocal (Jaiswal et al., 2000; David et al., 2007). The commitment of MSCs into osteogenic or adipogenic lineage is primarily regulated by activation or inhibition of ERK1/2, respectively (Jaiswal et al., 2000). Although there is no evidence supporting the involvement of ERK1/2 activation in determining the commitment of mechanical stimuli-induced cell differentiation, mechanical stimuli such as cyclic stretching have been shown to favour osteodifferentiation but inhibit the induction of adipogenesis (Tanabe et al., 2004; David et al., 2007). Moreover, mechanical stretching also exhibits the ability to activate ERK1/2 to promote cell osteogenic differentiation (Huang et al., 2009). These results may suggest that the reciprocal roles of mechanical stimuli on mediating cell osteogenic and adipogenic differentiation may be via a differently regulating ERK1/2 pathway. Recent animal studies have proved that LMHF vibration is able to conduct the lineage commitment of BMSCs by biasing cell fate in 
favour of osteogenesis over adipogenesis (Rubin et al., 2007; Luu et al., 2009). However, whether microvibrationactivated ERK1/2 signalling is involved in biasing the concomitant cell differentiation remains unknown. Further investigation may elucidate the exact role of microvibration induced-ERK1/2 activation on BMSC differentiation.

It has been proved that the addition of osteogenic cells into the scaffold before in vivo implantation could significantly promote bone formation and osteointegration due to osteogenic proteins secreted by these loaded cells (Cancedda et al., 2003; Mauney et al., 2004; Mauney et al., 2005; Zhu et al., 2006). MSCs are able to produce bone tissues and enhance the osteogenic ability of demineralised bone materials (Cancedda et al., 2003; Mauney et al., 2004; Mauney et al., 2005; Zhu et al., 2006). In vitro, we have demonstrated that osteogenic markers are greatly increased by microvibration stimuli. However, in response to microvibration, whether these markers can be highly expressed in BMSC cellular scaffolds after in vivo implantation is unknown. The transmissibility of wholebody vibration has been elucidated to have anabolic effects on skeletal homeostasis (Rubin et al., 2002; Rubin et al., 2007). There is ongoing effort in using BMSC cellular scaffolds to repair bone defects in animals to understand whether whole body microvibration shows any positive effect on the healing process of bone defects after in vivo implantation.

In conclusion, our study provided a first glimpse at how BMSCs seeded on bone-derived scaffolds respond to microvibration. BMSC differentiation appears to be mediated by microvibration. At the transcript and protein levels, microvibration drives gene and protein changes that favour osteogenesis. In addition, the activation of ERK1/2 plays an important role in microvibration-induced osteogenesis.

\section{Acknowledgements}

The authors are grateful to Prof. Chih-Ko Yeh (The University of Texas Health Science Center at San Antonio, TX, USA) for carefully reviewing and correcting mistakes in the manuscript, Dr. Xianwen Liu (State Key Laboratory of Oral Disease, Sichuan University, Chengdu, China) for providing technical support in Western Blot and Shu Wu (Beijing Dede Chuangye Technology Company Limited, Beijing, China) for helping bone-derived scaffold manufacturing. This study was supported by the National Science Foundation of China (Grant NO: 30772449).

\section{References}

Ashammakhi N, Ferretti P (2003) Topics in Tissue Engineering. E-book Chapter 5. (http://www.oulu.fi/ spareparts/ebook_topics_in_t_e/index.html).

Beck Jr GR (2003) Inorganic phosphate as a signaling molecule in osteoblast differentiation. J Cell Biochem 90: 234-243.
Burger EH, Klein-Nulend J (1999) Mechanotransduction in bone: role of the lacuno-canalicular network. FASEB J 13: S101-S112.

Cancedda R, Mastrogiacomo M, Bianchi G, Derubeis A, Muraglia A, Quarto R (2003) Bone marrow stromal cells and their use in regenerating bone. Novartis Found Symp 249: 133-143.

Colnot C, Romero DM, Huang S, Helms JA (2005) Mechanism of action of demineralized bone matrix in the repair of cortical bone defects. Clin Orthop Relat Res 435: 69-78.

David V, Martin A, Lafage-Proust MH, Malaval L, Peyroche S, Jones DB, Vico L, Guignandon A (2007) Mechanical loading down-regulates peroxisome proliferator- activated receptor $\gamma$ in bone marrow stromal cells and favors osteoblastogenesis at the expense of adipogenesis. Endocrinology 148: 2553-2562.

Deijkers RL, Bloem RM, Petit PL, Brand R, Vehmeyer SB, Veen MR (1997) Contamination of bone allografts: analysis of incidence and predisposing factors. J Bone Joint Surg Br 79: 161-166.

Ducy P, Zhang R, Geoffroy V, Ridall AL, Karsenty G. (1997) Osf2/Cbfa1: a transcriptional activator of osteoblast differentiation. Cell 89: 747-754.

Dumas V, Ducharne B, Perrier A, Fournier C, Guignandon A, Thomas M, Peyroche S, Guyomar D, Vico L, Ratter A (2010) Extracellular matrix produced by osteoblasts cultured under low-magnitude, high-frequency stimulation is favorable to osteogenic differentiation of mesenchymal stem cells. Calcif Tissue Int 87: 351-364.

Franceschi RT (1999) The developmental control of osteoblast-specific gene expression role of specific transcription factors and the extracellular matrix environment. Crit Rev Oral Biol Med 10: 40-57.

Frost HM (2003) Bone's mechanostat: a 2003 update. Anat Rec A Discov Mol Cell Evol Biol 275: 1081-1101.

Garman R, Gaudette G, Donahue L, Rubin C, Judex S (2007) Low-level accelerations applied in the absence of weight bearing can enhance trabecular bone formation. $\mathrm{J}$ Orthop Res 25: 732-740.

Goueli SA, Hsiao K, Lu T, Simpson D (1999) U0126: A novel, selective and potent inhibitor of MAP kinase kinase (MEK). Promega Notes 69: 6-8.

Gundberg CM, Nieman SD, Abrams S, Rosen H (1998) Vitamin K status and bone health: an analysis of methods for determination of undercarboxylated osteocalcin. J Clin Endocrinol Metab 83: 3258-3266.

Hess R, Douglas T, Myers KA, Rentsch B, Rentsch C, Worch H, Shrive NG, Hart DA, Scharnweber D (2010) Hydrostatic pressure stimulation of human mesenchymal stem cells seeded on collagen-based artificial extracellular matrices. J Biomech Eng 132: 021001.

Huang $\mathrm{CH}$, Chen MH, Young TH, Jeng JH, Chen YJ (2009) Interactive effects of mechanical stretching and extracellular matrix proteins on initiating osteogenic differentiation of human mesenchymal stem cells. J Cell Biochem 108: 1263-1273.

Huiskes R, Ruimerman R, van Lenthe GH, Janssen JD (2000) Effects of mechanical forces on maintenance and adaptation of form in trabecular bone. Nature 405: 704-706. 
Jaiswal RK, Jaiswal N, Bruder SP, Mbalaviele G, Marshak DR, Pittenger MF (2000) Adult human mesenchymal stem cell differentiation to the osteogenic or adipogenic lineage is regulated by mitogen-activated protein kinase. J Biol Chem 275: 9645-9652.

Judex S, Lei X, Han D, Rubin C (2007) Low-magnitude mechanical signals that stimulate bone formation in the ovariectomized rat are dependent on the applied frequency but not on the strain magnitude. J Biomech 40: 1333-1339.

Khan SN, Cammisa Jr FP, Sandhu HS, Diwan AD, Girardi FP, Lane JM (2005) The biology of bone grafting. J Am Acad Orthop Surg 13: 77-86.

Kim SH, Choi YR, Park MS, Shin JW, Park KD, Kim SJ, Lee JW (2007) ERK1/2 activation in enhanced osteogenesis of human mesenchymal stem cells in poly(lactic-glycolic acid) by cyclic hydrostatic pressure. J Biomed Mater Res A 80: 826-836.

Kinoshita S, Finnegan M, Bucholz RW, Mizuno K (1999) Three-dimensional collagen gel culture promotes osteoblastic phenotype in bone marrow derived cells. Kobe J Med Sci 45: 201-211.

Komori T, Yagi H, Nomura S, Yamaguchi A, Sasaki K, Deguchi K, Shimizu Y, Bronson RT, GaoYH, Inada M, Sato M, Okamoto R, Kitamura Y, Yoshiki S, Kishimoto T (1997) Targeted disruption of Cbfa1 results in a complete lack of bone formation owing to maturational arrest of osteoblasts. Cell 85: 755-764.

Langer R, Vacant JP (1993) Tissue engineering. Science 260: 920-926.

Lai CF, Chaudhary L, Fausto A, Halstead LR, Ory DS, Avioli LV, Cheng SL (2001) Erk is essential for growth, differentiation, integrin expression, and cell function in human osteoblastic cells. J Biol Chem 276: 14443-14450.

Lau E, Al-Dujaili S, Guenther A, Liu D, Wang L, You L (2010) Effect of low-magnitude, high-frequency vibration on osteocytes in the regulation of osteoclasts. Bone 46: 1508-1515.

Li HX, Han M, Bernier M, Zheng B, Sun SG, Su M, Zhang R, Fu JR, Wen JK (2010) Krüppel-like factor 4 promotes differentiation by transforming growth factor- $\beta$ receptor-mediated Smad and p38 MAPK signaling in vascular smooth muscle cells. J Biol Chem 285: 1784617856.

Luu YK, Capilla E, Rosen CJ, Gilsanz V, Pessin JE, Judex S, Rubin CT (2009) Mechanical stimulation of mesenchymal stem cell proliferation and differentiation promotes osteogenesis while preventing dietary-induced obesity. J Bone Miner Res 24: 50-61.

Mauney JR, Sjostorm S, Blumberg J, Horan R, O’Leary JP, Vunjak-Novakovic G, Volloch V, Kaplan DL (2004) Mechanical stimulation promotes osteogenic differentiation of human bone marrow stromal cells on 3-D partially demineralized bone scaffold in vitro. Calcif Tissue Int 74: 458-468.

Mauney JR, Jaquiery C, Volloch V, Heberer M, Martin I, Kaplan DL (2005) In vitro and in vivo evaluation of differentially demineralized cancellous bone scaffolds combined with human bone marrow stromal cells for tissue engineering. Biomaterials 26: 173-185.
Mistry AS, Mikos AG (2005) Tissue engineering strategies for bone regeneration. Adv Biochem Eng Biotechnol 94: 1-22.

Neven E, Persy V, Dauwe S, De Schutter T, De Broe ME, D'Haese PC (2010) Chondrocyte rather than osteoblast conversion of vascular cells underlies medial calcification in uremic rats. Arterioscler Thromb Vasc Biol 30: $1741-1750$

Norman-Taylor FH, Villar RN (1997) Bone allograft: a cause for concern? J Bone Joint Surg Br 79: 178-180.

Oh ES, Seo YK, Yoon HH, Cho H, Yoon MY, Park JK. (2010) Effects of sub-sonic vibration on the proliferation and maturation of 3T3-L1 cells. Life Sci 88: 169-177.

Patel MJ, Chang KH, Sykes MC, Talish R, Rubin C, Jo $H$ (2009) Low magnitude and high frequency mechanical loading prevents decreased bone formation response of 2T3 preosteoblasts. J Cell Biochem 106: 306-316.

Rattner A, Sabido O, Le J, Vico L, Massoubre C, Frey J, Chamson A (2000) Mineralization and alkaline phsophatase activity in collagen lattices populated by human osteoblasts. Calcif Tissue Int 66: 35-42.

Rosenthal RK, Folkman J, Glowacki J (1999) Demineralized bone implants for nonunion fractures, bone cysts, and fibrous lesions. Clin Orthop Relat Res 364: 6169.

Rubin C, Turner AS, Müller R, Mittra E, Mcleod K, Lin W, Qin YX (2002) Quantity and quality of trabecular bone in the femur are enhanced by a strongly anabolic, noninvasive mechanical intervention. J Bone Miner Res 17: 349-357.

Rubin C, Recker R, Cullen D, Ryaby J, McCabe J, McLeod K (2004) Prevention of postmenopausal bone loss by a low-magnitude, high-frequency mechanical stimuli: a clinical trial assessing compliance, efficacy, and safety. J Bone Miner Res 19: 343-351.

Rubin C, Capilla E, Luu YK, Busa B, Crawford H, Nolan DJ, Mittai V, Rosen CJ, Pessin JE, Judex S (2007) Adipogenesis is inhibited by brief, daily exposure to highfrequency, extremely low-magnitude mechanical signals. Proc Natl Acad Sci USA 104: 17879-17884.

Salkeld SL, Patron LP, Barrack RL, Cook SD (2001) The effect of osteogenic protein-1 on the healing of segmental bone defects treated with autograft or allograft bone. J Bone Joint Surg Am 83: 803-816.

Silber JS, Anderson DG, Daffner SD, Brislin BT, Leland JM, Hilibrand AS, Vaccaro AR, Albert TJ (2003) Donor site morbidity after anterior iliac crest bone harvest for single-level anterior cervical discectomy and fusion. Spine 28: 134-139.

Simion M, Fontana F (2004) Autogenous and xenogeneic bone grafts for the bone regeneration. Minerva Stomatol 53: 191-206.

Simmons CA, Matlis S, Thornton AJ, Chen S, Wang CY, Mooney DJ (2003) Cyclic strain enhances matrix mineralization by adult human mesenchymal stem cells via the extracellular signal-regulated kinase (ERK1/2) signaling pathway. J Biomech 36: 1087-1096.

Tadjoedin ES, de Lange GL, Bronckers AL, Lyaruu DM, Burger EH (2003) Deproteinized cancellous bovine 
bone (Bio-Oss) as bone substitute for sinus floor elevation. J Clin Periodontal 30: 261-270.

Tanabe Y, Koga M, Saito M, Matsunaga Y, Nakayama K (2004) Inhibition of adipocyte differentiation by mechanical stretching through ERK-mediated downregulation of PPARgmma 2. J Cell Sci 117: 3605-3614.

Tanaka SM, Li J, Duncan RL, Yokota H, Burr DB, Turner CH (2003) Effects of broad-frequency vibration on cultured osteoblast. J Biomech 36: 73-80.

Turner CH, Owan I, Takano Y (1995) Mechanotransduction in bone: role of strain rate. Am J Physiol 269: E438-E442.

Wang FS, Wang CJ, Sheen-Chen SM, Kuo YR, Chen RF, Yang KD (2002) Superoxide mediates shock wave induction of ERK-dependent osteogenic transcription factor (Cbfa1) and mesenchymal cell differentiation toward osteoprogenitors. J Biol Chem 277: 10931-10937.

Ward K, Alsop C, Caulton J, Rubin C, Adams J, Mughal Z (2004) Low magnitude mechanical loading is osteogenic in children with disabling conditions. J Bone Miner Res 19: $360-369$.

Weyts FA, Li YS, van Leeuwen J, Weinans H, Chien S (2002) ERK activation and alpha $v$ beta 3 integrin signaling through Shc recruitment in response to mechanical stimulation in human osteoblasts. J Cell Biochem 87: 8592.

Xiao G, Jiang D, Thomas P, Bension MD, Guan K, Karsenty G, Franceschi RT (2000) MAPK pathways activate and phosphorylate the osteoblast-specific transcription factor, Cbfa1. J Biol Chem 275: 4453-4459.

Xiao G, Jiang D, Gopalakrishnan R, Franceschi RT (2002) Fibroblast growth factor 2 induction of the osteocalcin gene requires MAPK activity and phosphorylation of the osteoblast transcription factor, Cbfa1/Runx2. J Biol Chem 277: 36181-36187.

Xiao G, Gopalakrishnan R, Jiang D, Reith E, Benson MD, Franceschi RT (2002) Bone morphogenetic proteins, extracellular matrix, and mitogen-activated protein kinase signaling pathways are required for osteoblast-specific gene expression and differentiation in MC3T3-E1 cells. J Bone Miner Res 17: 101-110.

Xie L, Jacobson JM, Choi ES, Busa B, Donahue LR, Miller LM, Rubin CT, Judex S (2006) Low-level mechanical vibrations can influence bone resorption and bone formation in the growing skeleton. Bone 39: 10591066.

Xu H, Shimizu Y, Asai S, Ooya K (2003) Experimental sinus grafting with the use of deproteinized bone particles of different sizes. Clin Oral Implants Res 14: 548-555.

Zhou Y, Guan XX, Zhu ZL, Guo J, Huang YC, Hou WW, Yu, HY (2010) Caffeine inhibits the viability and osteogenic differentiation of rat bone marrow-derived mesenchymal stromal cells. Br J Pharmacol 161: 15421552.

Zhu L, Liu W, Cui L, Cao Y (2006) Tissue-engineered bone repair of goat-femur defects with osteogenically induced bone marrow stromal cells. Tissue Eng 12: 423 433.

Ziros PG, Gil AP, Georgakopoulos T, Habeos I, Kletsas D, Basdra EK, Papavassiliou AG (2002) The bone-specific transcriptional regulator Cbfa1 is a target of mechanical signals in osteoblastic cells. J Biol Chem 277: 2393423941.

\section{Discussion with Reviewers}

Reviewer I: The extracellular matrix of bones is made out of proteins and a mineral phase. What is left when the human bone is demineralised and deproteinised like in this study?

Authors: The bone extracellular matrix has two main components (Sommerfeldt and Rubin, 2001, additional reference). Of the matrix, $65-70 \%$ is the mineral part consisting of hydroxyapatite. The remainder is the organic part consisting of proteins such as collagen I, osteocalcin, osteopontin, osteonectin, fibronectin, biglycan, and bone sialoprotein. A series of physical and chemical procedures was conducted to process scaffolds in our study, including partial demineralisation by $0.6 \mathrm{~N}$ hydrochloric acid, partial deproteinisation by 1:1 chloroform/methanol and lyophilisation and sterilisation by $60 \mathrm{Co} \gamma$-ray irradiation. The partial demineralisation can expose both soluble and insoluble osteogenic factors from calcified matrix, including bone morphogenetic proteins and other noncollagenous proteins (Rosenthal et al., 1999; Colnot et al., 2005, text references). Therefore, what is left in the scaffolds is demineralised hydroxyapatite and some proteins released from decalcifying matrix even after partial deproteinisation.

Reviewer I: If microvibrations improve osteoblast differentiation, would we improve the system by applying a constant treatment instead of a 30 min treatment every $12 \mathrm{~h}$ ?

Authors: It has been recently been shown by many in vivo studies that LMHF vibration and other kinds of mechanical stimuli exhibit favourable influence on bone homeostasis (Rubin et al., 2002; Rubin et al., 2004; Ward et al., 2004; Garman et al., 2007; Rubin et al., 2007, text references; Rubin et al., 2001; Maddalozzo et al., 2008; de Oliveira et al., 2010, additional references). Although the anabolic role of LMHF vibration on bone is achieved by different magnitudes and frequencies of vibration produced with different devices, the time for vibration imposed on these objects is temporal and intermittent. Additionally, in in vitro studies, LMHF vibration has been demonstrated to promote cell osteogenic differentiation and inhibit osteoclast activity when cells were exposed to vibrations for 10-60 min/d (Patel et al., 2009; Lau et al., 2010, text references). In our preliminary study, ALP activity was significantly decreased when BMSCs seeded on scaffolds were treated with vibration for a whole day. Bone is a complicated biological system and the process of bone formation and bone resorption needs mechanical stimuli (Burger and Klein-Nulend, 1999; Huiskes et al., 2000; Frost, 2003, text references). However, under physiological conditions, bone experiences temporal and intermittent - but not constant mechanical stimuli. Therefore, our vibration protocol is appropriate for mimicking physiological conditions. 
Reviewer II: Why did the authors choose to combine rat BMSCs with human bone-derived scaffolds?

Authors: The aim of our study is firstly to demonstrate that in vitro microvibration exhibits a favourable influence on osteogenic differentiation of BMSCs seeded on bone-derived scaffolds, and then to understand whether microvibration shows any positive influence on the healing process of bone defects after in vivo implantation by using BMSC cellular scaffolds to repair bone defects in an animal study. Rat is a convenient model to create a bone defect (Kikuchi et al., 2008, additional reference). Moreover, the diameter of rat femur is $4.24 \pm 0.08 \mathrm{~mm}$ (Beall et al., 1984, additional reference). Considering the size of scaffold presented in our study, it may be easy for us to remould the shape of scaffolds and then repair the bone defects after creating bone defects in rat femur. In addition, given that using the xenogenic BMSCs cellular scaffolds may cause immune reaction after in vivo implantation in rats, we thus decided to choose to combine rat BMSCs with human bone-derived scaffolds. As shown in our study, rat BMSCs attached well in the porous scaffolds and experienced osteogenic differentiation. However, whether the processed scaffolds in our study can be further used in the clinic remains unknown. In our opinion, an animal study is the first step to understand how these BMSC cellular scaffolds function in vivo.

Reviewer II: Can you imagine clinical applications of this special method? How would such a setting look like? Authors: The sensor presented in our study may be not suitable for clinical use. Therefore, significant changes to the device need to be carried out if clinical application is required. For example, to the best of our imagination, when patients receive an in vivo implantation in their limbs, we can put a platform under the surgical site. The surface shape of platform must mimic the outline of limbs so patients will feel comfortable when their limbs are placed on the platform. Once limbs are fixed on the platform, we adjust the parameters of microvibration produced by sensor and the signalling can be transferred to the platform by a transmitter (e.g., a cable). Thus, patients can receive local body microvibration to accelerate the healing process. However, when patients receive more than one in vivo implant in different body parts, whole body microvibration will be much better, and placing the sensor under the patient's bed will be a good method. Anyway, modification on the device to suit clinical needs may require knowledge from different specialities, including medical science, mechanics, and so on. In our opinion, animal experiments should be the first step to test whether microvibration exhibits any positive effects on the healing process of bone defects after in vivo implantation.

Reviewer II: Are there any possible restrictions to the types of stem cells used for this special approach? Could one make use of cells other than BMSCs?

Authors: The scaffolds derived from bone may mainly be used in bone tissue engineering. As shown in our study, the bone-derived scaffolds show osteoinductive property. So any type of stem cells that is capable of differentiating into osteogenic lineage and is able to attach on the surface of scaffolds should be useful for this cell-scaffold composite. Among various stem cells, MSC, primarily originating from mesenchymal tissues, can be differentiated into a variety of cell types, including osteoblasts and chondrocytes (Pittenger et al., 1999, additional reference). Therefore, MSC derived from other non-bone marrow tissues, such as umbilical cord blood, adipose tissue, muscle or the dental pulp of deciduous baby teeth (Pittenger et al., 1999; Minguell et al., 2001; Huang et al., 2009, additional references) could be proposed as a promising cell resource for this cell-scaffold composite.

Reviewer III: If the aim of the study is to evaluate the role of body microvibration on osteogenesis involved in vivo scaffold implantation, is it possible to assimilate the LMHF applied on the scaffold and the body microvibrations in terms of magnitude and frequency?

Authors: The microvibration regimen was determined based on existing literatures and our preliminary studies. The optimal parameters of vibration in our study are different from those in vitro and in vivo studies (Rubin et al., 2002; Rubin et al., 2004; Garman et al., 2007; Lau et al., 2010; Patel et al., 2009, text references; Rubin et al., 2001; Maddalozzo et al.; 2008, de Oliveira et al., 2010, additional reference). The disparity may due to the various factors, including different devices to produce vibration, different culturing environment and cell types for in vitro study, different subjects for in vivo study, and different conditions between in vivo and in vitro study. The purpose of our next study is to understand whether microvibration shows any positive influence on the healing process of bone defects after in vivo implantation by using BMSC cellular scaffolds to repair bone defects in animals. We plan to use rats as animals. The rats receiving in vivo implantation will be placed in a cage that can be tightly placed in a fixture. By fastening the fixture into the platform of the sensor, the rats can receive body microvibration at about the magnitude $(0.3 \mathrm{~g})$ and frequency $(40 \mathrm{~Hz})$ described in our in vitro study.

Reviewer IV: How can you explain that the DNA content increases (Fig. 3) whereas the incorporation of thymidine decreases?

Authors: Thymidine is a labelled DNA precursor. Once a cell divides, it will be incorporated into the cell's DNA. Therefore, the level of radioactive signal depends on the proliferation rate. The higher the proliferation rate, the more cells can be harvested thus the more radioactive DNA and accordingly the higher signal. Based on the principle of thymidine incorporation, to get higher signal, cells should firstly be viable and secondly be proliferative. The scaffolds and microvibration presented in our study show ability to promote osteogenic differentiation, thus the proliferative cells will decrease as the osteogenesis process goes on. Since these differentiated cells can't undergo cell division, the radioactive signal (CPM) will become weaker and weaker as osteogenesis goes on. As for DNA content, it reflects cell number. The more the number of cells, regardless of whether cells are differentiated or 
remain viable, the higher DNA content will be achieved. Moreover, although more and more cells experience osteogenic differentiation in our study, there are still some cells can proliferate and DNA content will thus increase.

\section{Additional References}

Beall PT, Misra LK, Young RL, Spjut HJ, Evans HJ, LeBlanc A (1984) Clomiphene protects against osteoporosis in the mature ovariectomized rat. Calcif Tissue Int 36: 123-125.

De Oliveira ML, Bergamaschi CT, Silva OL, Nonaka KO, Wang CC, Carvalho AB, Jorgetti V, Campos RR, Lazaretti-Basto M (2010) Mechanical vibration preserves bone structure in rats treated with glucocorticoids. Bone 46: 1516-1521.

Huang GTJ, Gronthos S, Shi S (2009) Mesenchymal stem cells derived from dental tissues $v s$. those from other sources: regenerative medicine. J Dent Res 88: 792-806.
Kikuchi T, Kubota S, Asaumi K, Kawaki H, Nishida T, Kawata K, Mitani S, Tabata Y, Ozaki T, Takigawa M (2008) Promotion of bone regeneration by CCN2 incorporated into gelatin hydrogel. Tissue Eng Part A 14: 1089-1098.

Maddalozzo GF, Iwaniec UT, Turner RT, Rosen CJ, Widrick JJ (2008) Whole-body vibration slows the acquisition of fat in mature female rats. Int $\mathrm{J}$ Obes 32: 1348-1354.

Minguell JJ, Erices A, Conget P (2001) Mesenchymal stem cells. Exp Biol Med 226: 507-520.

Pittenger MF, Mackay AM, Beck SC, Jaiswal RK, Douglas R, Mosca JD, Moorman MA, Simonetti DW, Craig S, Marshak DR (1999) Multilineage potential of adult human mesenchymal stem cells. Science 284: 143-147.

Rubin C, Turner A, Bain S, Mallinckrodt C, McLeod K (2001) Anabolism: low mechanical signals strengthen long bones. Nature 412: 603-604.

Sommerfeldt DW, Rubin CT (2001) Biology of bone and how it orchestrates the form and function of the skeleton. Eur Spine J Suppl 2: S86-S95. 